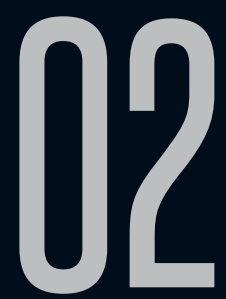

\title{
A LITERATURA FANTÁSTICA: CAMINHOS TEÓRICOS. ANA LUIZA SILVA CAMARANI. 2014.
}

Adelaide Caramuru Cezar (UNESP)

Recebido em 08 mai 2015. Adelaide Caramuru Cezar possui doutorado (1996) e Aprovado em 27 nov 2015. mestrado (1988) em Teoria da Literatura e Literatura Comparada pela Universidade Estadual Paulista Júlio Mesquita Filho. Atualmente é professor associado $\mathrm{C}$ da Universidade Estadual de Londrina. Tem experiência na área de Teoria da Literatura, Literatura Brasileira e Literatura Comparada, atuando principalmente com os seguintes temas: fantástico, grotesco, contos de Machado de Assis, contos de João Guimarães Rosa. É membro associado do seguinte GT da ANPOLL: Vertentes do Fantástico Ficcional. 
UM PÉRIPLO PELOS TERRITÓRIOS TEÓRICOS DO FANTÁSTICO

Ana Luiza Silva Camarani, professora de Literatura Francesa e Literatura Comparada na Universidade Estadual Paulista Júlio de Mesquita Filho, UNESP, campus de Araraquara, efetivou estágio pós-doutoral na Universidade de São Paulo entre os anos 2013 e 2014. O livro agora resenhado, A literatura fantástica: caminhos

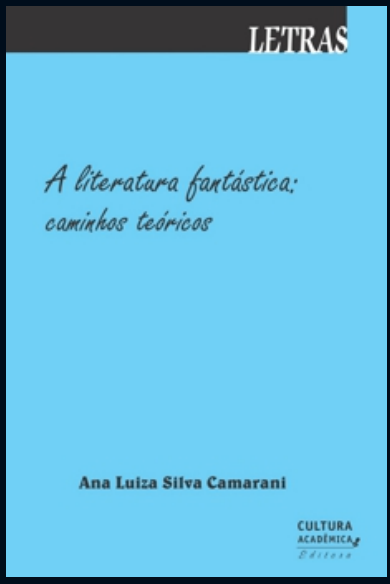
teóricos, é resultante da pesquisa efetivada sob a supervisão da Profa Dra. Glória Carneiro do Amaral nesse momento de sua pesquisa.

Logo na "Introdução" de seu trabalho, Camarani aponta problema central para a definição de uma narrativa fantástica: a grande proximidade com o romance gótico e o realismo mágico. A distinção entre as três modalidades, segundo a autora, reside no fato de que, na narrativa fantástica, a ambiguidade e a incerteza são resultantes das manifestações do insólito, seja ele estranho, mágico ou sobrenatural; no romance gótico, esses elementos, sendo explícitos, não geram incerteza nem ambiguidade; já no realismo mágico é eliminada a oposição real/insólito, havendo, como diz a estudiosa, "a naturalização do sobrenatural ou a sobrenaturalização do real" (CAMARANI, A literatura fantástica: caminhos teóricos. São Paulo, SP: Cultura Acadêmica, 2014. p. 8) ${ }^{1}$. $\mathrm{O}$ grande destaque dado à proximidade destas três modalidades a dificultar o entendimento é enfatizado através de pareceres número da página. 
de dois renomados teóricos/críticos do fantástico na atualidade: Malrieu e Alazraki. No trabalho de Camarani, Joël Malrieu é estudado em todo um tópico do terceiro capítulo: "Joël Malrieu e a valorização do personagem". A Jaime Alazraki, infelizmente, resta apenas a referência feita na "Introdução" agora enfocada.

Levantada a problemática maior, é chegado o momento do (1) objetivo do trabalho: apresentar "reflexões e discussões sobre o fantástico tradicional, que continua a ser desenvolvido durante o século XX por alguns escritores, embora seu ápice tenha sido o século XIX" (p. 8); (2) sua divisão em capítulos: "Reflexões teóricas e críticas precursoras", onde se fazem presentes Charles Nodier (1780-1844), Guy de Maupassant (1850-1899) e Pierre GeorgeCastex (1915-1995); "Textos fundadores", onde se encontram Louis Vax (1924- ), Roger Caillois (1913-1978), Tzvetan Todorov (1939- ), Jean Bellemin-Noël (1931- ), Irène Bessière ( - )²; “A evolução da teoria", fazendo-se presentes Jacques Finné (1944), Filipe Furtado ( - ), Joël Malrieu ( - ), Valérie Tritter ( - ), Remo Ceserani (1933- ), Michel Viegnes (1959- ), David Roas (1965- ); "Teoria e crítica no Brasil", com a presença de José Paulo Paes (1926-1998) e Selma Calasans Rodrigues ( - ).

Descrito o percurso, a autora ressalta a presença de Freud (1856-1936), Lovecraft (1890-1937), Sartre (1905-1980) e Marcel Schneider ( - ) no decorrer do trabalho bem como a escolha pela denominação "modalidade literária", à maneira de Ceserani, deixando de lado a denominação do fantástico como gênero, subgênero ou categoria, efetivados por outros teóricos/críticos.

2 Como há no trabalho ordem cronológica, serão mantidos os anos de nascimento (e morte) dos estudiosos. Alguns deles, sendo desconhecida a data de nascimento e morte, serão mantidos os espaços em branco, cabendo ao leitor situá-los aproximativamente no tempo. 
Camarani inicia o primeiro capítulo de seu livro com afirmação categórica: "Se Cazotte foi o precursor da literatura fantástica, Charles Nodier (1780-1844) pode ser considerado precursor no que tange às reflexões teóricas sobre o fantástico" (p. 13). Registra a data de seu primeiro ensaio, "Do fantástico em literatura": 1830. Este é, pois, o marco inicial dos estudos sobre o fantástico na França. Insere o estudioso entre aqueles que, assim como Vax, no século $X X$, veem no fantástico a confrontação do real com o impossível, devendo o real representado no texto remeter ao real conhecido pelo leitor, bem como "a necessidade de identificação entre as palavras do contador de história e o público, isto é, a necessidade de crença (ou a qualidade de ser convicto) por parte do contista" (p. 49). Coube-Ihe, segundo a estudiosa araraquarense, o enfoque da efervescência do fantástico pós Revolução Francesa como resultante da fadiga do público "por séculos de racionalismo" (p. 15). Nodier, segundo Camarani, preparou caminho para E. T. A. Hoffmann (1766-1822) na França não só por suas traduções de contos do escritor alemão, mas, principalmente, por seu papel centralizador do Romantismo em seu momento inicial. Para mostrar a importância do sonho e da loucura na obra do estudioso, há recorrência aos seus contos.

Guy de Maupassant (1850-1899), segundo autor enfocado na obra aqui resenhada, é estudado principalmente em duas crônicas escritas para o jornal Le Galois. Na primeira, de novembro de 1881, o autor se despede do primeiro fantástico, aquele abordado por Nodier, destacando que "a noite não mais aterroriza o homem, para quem não há mais fantasmas, nem espíritos, pois tudo o que era chamado 'fenômeno' é explicado por leis naturais" (p. 23). 
Na segunda, de outubro de 1883, há elogio à obra de Ivan Turguêniev (1818-1883). Aí o estudioso enfoca dois momentos do fantástico. O primeiro é aquele apresentado por Nodier, do qual falou na crônica anterior. O segundo trata do fantástico posterior ao positivismo e à industrialização. Registra a sutileza presente nesse novo fantástico no qual a hesitação, a dúvida, o estranhamento se constituem como constantes, antecipando por suas colocações afirmações de Todorov, Bessière, Vax e Freud.

Pierre-Georges Castex (1915-1995) faz-se presente através de Le conte fantastique en France de Nodier à Maupassant, de 1951. Aí o autor, segundo a professora araraquarense, retorna à segunda metade do século XVIII, enfatizando o papel das ciências ocultas para o desenvolvimento do fantástico. Jacques Cazotte é apresentado como precursor francês desta modalidade literária, cabendo, no entanto, à tradução da obra de E. T. A. Hoffmann na França a definitiva denominação "fantástico" para esta nova modalidade literária que teve no conto seu pleno desenvolvimento. São apresentados consecutivamente os autores de maior destaque da literatura francesa que se dedicaram ao conto fantástico, enfatizando a importância do sonho e da loucura na evolução do fantástico do século XIX.

Inicia-se então o segundo capítulo do livro: "Textos fundadores: Vax, Caillois, Todorov, Bellemin-Noël, Bessiére". O primeiro deles, Louis Vax (1924- ) é apresentado através de duas obras: A arte e a literatura fantástica, de 1960, e La séduction de l'étrange, de 1965. Quando desenvolve seu trabalho, Camarani limita-se a uma referência à primeira das duas publicações, sendo em verdade bastante significativa: 
A narrativa fantástica, pelo contrário, gosta de nos apresentar, habitando o mundo real onde nos encontramos, homens como nós, postos de súbito em presença do inexplicável. [...] O fantástico nutre-se dos conflitos do real e do possível (CAMARANI, 2014, p. 43).

Feita esta citação, Camarani parte para o exame da segunda publicação de Vax, destacando sua ambição filosófica. Para o estudioso, existe uma estrutura de obra fantástica, mas esta se caracteriza por sua constante mobilidade. O ensaio "O inquietante", de Freud, é cuidadosamente estudado pelo autor.

Roger Caillois (1913-1978) é apresentado através de duas obras publicadas em 1966: Anthologie du fantastique, no qual Camarani se atém ao prefácio: "De la féerie à la science-fiction", e Images, images...: essais sur le rôle et les pouvoirs de l'imagination. Sua grande preocupação reside na diferenciação entre contos de fadas, narrativas fantásticas e ficção científica. O sobrenatural em cada uma dessas modalidades possui especificidade: nos contos de fadas, ele é aceito como constituinte desse universo. No fantástico, ele é "impossível chegando de improviso em um mundo do qual foi banido por definição" (p. 55). Já na narrativa fantástica, o sobrenatural é, em verdade, mera encenação, ou, muitas vezes, mero sonho ou alucinação do herói a ser resolvida antes do término da narrativa. O medo é apresentado como componente fundamental do fantástico.

Tzvetan Todorov (1939- ) ocupa o segundo maior espaço textual na obra analisada, sendo apenas superado por Michel Viegnes, abordado pelo enfoque do vínculo do fantástico com a poesia. Ao ater-se ao papel desempenhado por Todorov nos estudos 
literários, Camarani vai seguindo Introdução à literatura fantástica, vendo progressiva e criticamente sua contribuição. O emprego da primeira pessoa do singular, que até o presente momento do trabalho de Camarani não ocorria, começa a ser empregado, pontuando discordâncias da estudiosa araraquarense frente aos posicionamentos do autor: "Vejo aqui outra contradição, uma vez que[...]" (p. 64, grifo meu); "Novamente remeto à estrutura que Todorov propõe - a qual considero plenamente válida no que se refere ao fantástico tradicional - e pergunto-me[...]" (p. 65, grifos meus). O enfoque dado ao posicionamento de Todorov frente ao fantástico começa pelo fato de o estudioso situá-lo como gênero literário. Sua segunda preocupação reside em apontar o caráter estruturalista da abordagem da narrativa fantástica pelo autor. Vax, que será um autor sempre destacado pela estudiosa araraquarense, é apontado como antecessor direto de Todorov na busca por uma abordagem estruturalista da obra fantástica. Os três aspectos apresentados pelo estudioso búlgaro como compositivos da estrutura literária - verbal, sintático e semântico - são apresentados e cuidadosamente sintetizados, bem como as condições para a narrativa fantástica, girando em torno da hesitação (hesitação dos personagens, hesitação do leitor, não aceitação da interpretação alegórica ou poética da narrativa fantástica pelo receptor). Insere-se na leitura de Camarani sobre o texto de Todorov o enfoque de O horror sobrenatural em literatura, de Lovecraft. O medo, apontado pelo escritor estadunidense como condição sine qua non do fantástico, é o responsável por essa inserção, ressaltando a autora a não aceitação de Todorov do medo como elemento estrutural da narrativa fantástica. 
Feita essa ressalva, Camarani retorna à hesitação como uma das responsáveis pela ambiguidade na narrativa, colocando lado a lado a esta geradora, o emprego do pretérito imperfeito e a modalização. Atém-se a autora ao estabelecimento dos subgêneros do fantástico: (1) fantástico-estranho; (2) estranho puro; (3) fantástico-maravilhoso; (4) maravilhoso puro. A leitura progride, capítulo após capítulo, sempre cuidadosa, sempre criteriosa, de maneira a apontar, ao final, a curta duração do fantástico: do final do século XVIII ao início do século $X X$, "[...] onde a coisa mais surpreendente é a ausência de surpresas diante [de um] acontecimento inaudito" (p. 72). Concluindo o tópico, a autora destaca que "como o teórico cita Kafka, concluise que esteja remetendo ao que Sartre chama de fantástico contemporâneo e que, mais tarde, a crítica especializada denominará realismo mágico" (p. 72).

Jean Bellemin-Noël (1931 - ) faz-se presente através de dois ensaios: "Des formes fantastiques aux thèmes fantastiques", de 1971, e "Notes sur le fantastique (textes de Théophile Gautier)", de 1972. No primeiro deles, segundo Camarani, critica o conhecido quadro de Todorov no qual coloca o fantástico entre o estranho e o maravilhoso. Propõe substituí-lo pela diferenciação entre fantástico, maravilhoso e ficção científica de acordo com quatro níveis de análise: (1) o ponto de vista; (2) o tipo de narração; (3) aa descrição; (4) a escritura romanesca realista. No segundo dos dois ensaios, elogia Todorov por ter buscado "características formais do fantástico literário" (p.80) e também por ter introduzido a possibilidade de enfoque psicanalítico da obra fantástica. A partir desta segunda colocação, adentra-se, segundo a estudiosa 
araraquarense, no ensaio "Das Unheimlich", de Freud, e conclui que "só há percepção fantástica no texto se a 'fantasticidade' for enfatizada pelo próprio discurso, pois é o discurso e não o evento que qualifica a história" (p. 83). Cinco são os procedimentos apontados por Bellemin-Noël: (1) a mise en abyme; (2) "efeito de espelho"; (3) "efeito de fantástico propriamente dito"; (4) "efeito de citação"; (5) "efeito referência explícita". Ana Luiza Camarani explica cuidadosamente cada um desses procedimentos apontados por Bellemin-Noël como auxiliares na constituição de uma narrativa fantástica.

"Bessière e a poética do incerto" é o quinto e último tópico referente ao segundo capítulo da obra agora resenhada. Fazse presente através da publicação de 1974: Le récit fantastique: la poétique de l'incertain. Logo de saída, Camarani afirma que a estudiosa francesa não compartilha da compreensão de fantástico como gênero nem como categoria literária, "mas supõe uma lógica narrativa" (p. 84). Esta se constrói a partir de duas possibilidades: (1) de maneira racional e empírica "(lei física, sonho, delírio, ilusão visual)" (p. 86); (2) de maneira racional e meta-empírica "(mitologia, teologia dos milagres e dos prodígios, ocultismo, etc)" (p. 86). Há na obra de Bessière constante diálogo com seus antecessores, principalmente com Sartre, dada sua preocupação com a renovação do fantástico a partir do início do século $X X$. Bessière atém-se às características do "fantástico contemporâneo" apontadas por Sartre em "Aminadab, ou o fantástico considerado como uma linguagem":

A rebelião dos meios contra os fins, pois nenhum meio é encontrado para realizar esse fim; o 
absurdo configurado pela ausência total de fim; a atmosfera asfixiante; a configuração de um mundo às avessas, onde as mensagens não têm conteúdo, nem mensageiro, tampouco remetente; a ausência de espanto diante da sucessão de acontecimentos desse mundo invertido que escandalizam em consequência de ser algo censurável, mas completamente normal; um universo em que a lei não apresenta finalidade, nem significado, e da qual ninguém pode fugir; um universo simultaneamente fantástico e rigorosamente verdadeiro. Esse universo fantástico teria o aspecto de uma burocracia (BESSIÈRE, 1974, p. 89-90).

Bessière, segundo Camarani, aborda a "naturalização do irreal" nas obras do século XX, atendo-se significativamente em contos de Cortázar e de Borges nos quais o sobrenatural é naturalizado, como é o caso, por exemplo, de "Azolotle", de "A noite de barriga para cima", de Cortázar, presentes em Final do jogo, e de "O Sul", de "As ruínas circulares", de Jorge Luis Borges, presentes em Ficções.

Não se pode deixar de ressaltar que a professora araraquarense, antes de terminar seu enfoque da importância de Irène Bessière para os estudos do fantástico, enfatiza sua importância nas reflexões sobre o fantástico tradicional, seja sobre "a lógica narrativa e a ruptura da causalidade" (p. 93), seja sobre a "presença de dados contraditórios reunidos seguindo uma coerência e complementaridade próprias" ( $p$. 93), seja ainda mostrando "ser próprio da narrativa fantástica atribuir a mesma inconsistência ao real e ao sobrenatural" (p. 93).

O terceiro capítulo, "A evolução da teoria" é dedicado a sete autores, indiciando junto ao nome de cada um dos estudiosos seu maior destaque nas pesquisas sobre o fantástico. Assim sendo, 
Jacques Finné (1944 - ) se distingue pela noção de "explicação narrativa". Para o estudioso belga, segundo Camarani

a narrativa se subdivide em dois vetores: um vetor de tensão, que se centra nos mistérios e tem por efeito contrair o leitor; um vetor de distensão, que aniquila a tensão. O ponto de junção entre os dois vetores é marcado pela explicação (CAMARANI, 2014, p. 101).

Ela pode (1) "aparecer no início ou no final da narrativa" ( $p$. 101); (2) "levar a uma solução racional ou irracional" (p. 101); (3) "possibilitar a escolha do leitor entre a explicação realista e a sobrenatural" (p. 101). Surge então um termo que pode confundir-se com "explicação narrativa": "sopro fantástico". Camarani aqui se adentra no texto de Jacques Finné, fazendoIhe séria oposição, recorrendo a exemplo da literatura brasileira ("O encontro", de Lygia Fagundes Telles) para opor-se à excessiva liberdade vislumbrada pelo estudioso na recepção do leitor.

"Filipe Furtado e a construção do fantástico na narrativa" é o título do segundo tópico deste terceiro capítulo. Aqui Camarani torna-se mais didática e destaca em negrito os pontos por ela tidos como importantes na teoria do professor português. O primeiro deles diz respeito ao enfoque da literatura fantástica como gênero literário no qual há o "surgimento do sobrenatural em um ambiente cotidiano e familiar" (p. 107), sendo "a fenomenologia metaempírica (de índole maléfica), o elemento temático dominante" (p. 107-108). A ambiguidade é o segundo ponto de destaque, enfatizando a necessária plausibilidade da intriga obtida através de procedimentos narrativos. A hesitação, segundo Furtado, conforme afirma Camarani, restringe-se à figura do narratário, 
não estando, pois, exposta a "reações aleatórias e exteriores à obra" (p. 113). O quarto destaque oferecido pela autora do livro diz respeito à identificação do leitor "com o personagem que melhor reflita a percepção ambígua do evento supostamente sobrenatural e sua consequente perplexidade diante da coexistência das duas fenomenologias contraditórias" (p. 113). Finalmente, dois são os últimos destaques: a) 0 narrador-personagem é "a modalidade mais frequente da narrativa fantástica" (p. 114); b) a descrição do cenário deve efetivar-se de maneira regrada e segura.

"Joël Malrieu e a valorização do personagem" é o tópico que recebe o menor espaço na obra de Camarani: cinco páginas. Há neste espaço apenas uma marcação em negrito: a definição dada pelo autor de literatura fantástica:

A narrativa fantástica assenta-se em última instância na confrontação de um personagem isolado com um fenômeno, exterior a ele ou não, sobrenatural ou não, mas cuja presença ou intervenção representa uma contradição profunda com os quadros de pensamento e de vida do personagem, a ponto de desordená-los completamente ou duravelmente (CAMARANI, 2014, p. 119-120, tradução minha).

Esta definição é amplamente comentada pela professora araraquarense. Ao final desse tópico, critica a utilização por Malrieu de textos pertencentes à literatura gótica ao tratar de literatura fantástica.

Como aconteceu no enfoque da obra de Malrieu, no tópico seguinte, "Valérie Tritter: a retomada do fantástico como forma movente", apenas a definição de fantástico oferecida por Tritter 
recebe a marcação em negrito: "o fantástico se apresenta como uma forma movente capaz de abarcar todos os gêneros literários existentes, mas alguns de maneira mais eficaz, no que diz respeito ao efeito produzido, do que outros" (p. 126, tradução minha). Camarani percorre a obra da professora francesa como um todo, destacando, ao final, que,

se Tritter (2001) não sugere novos elementos para a teoria do fantástico literário, apresenta os aspectos já existentes sob um novo olhar, inserindo-os nas diferentes abordagens que nomeiam os capítulos de seu estudo (CAMARANI, 2014, p. 130).

Ao Remo Ceserani (1933 - ) são dedicadas onze páginas do livro de Camarani. Apenas a partir da sétima página começam as didáticas marcações em negrito presentes de maneira mais enfática nesse terceiro capítulo de seu livro. O tópico recebe o seguinte título: "Remo Ceserani: o fantástico como modalidade literária". Este título é muito bem explicado nas três primeiras páginas do tópico, onde Camarani, concluindo, afirma:

a respeito da opção por considerar o fantástico como uma modalidade literária, a partir de Vax (1965) e posteriormente de Bessière, reitero a mobilidade da escrita do fantástico, que o torna apto a manifestar-se e desenvolver-se nos gêneros épico, lírico e dramático (CAMARANI, 2014, p. 133).

Nas últimas cinco páginas dedicadas a Ceserani, a professora da UNESP atém-se detalhadamente aos procedimentos formais do fantástico e aos sistemas temáticos do mesmo. Concluindo, Ana Luiza Silva Camarani, deixando claro seu gosto pelo texto de Ceserani, afirma: 
Para provar essas reflexões e reiterar a ponderação de ser o fantástico um modo literário, Ceserani busca mostrar sua transformação na história literária, apresentando seu desenvolvimento ou seus encontros com o esteticismo e o realismo do final do século XIX, como surrealismo e o neofantástico do século XXe com a pós-modernidade. Assim, na esteira das ponderações de Sartre, e depois de Bessière (1974), o crítico, em poucas páginas finais, e a partir das reflexões do crítico argentino Jaime Alazraki e de textos ficcionais do autor, também argentino, Julio Cortázar, medita sobre o que indica ser uma abertura para o absurdo. No mesmo sentido, apresenta breves considerações a respeito do escritor italiano Antonio Tabucchi e da experiência pós-moderna de revisitar modos ou gêneros literários do passado (CAMARANI, 2014, p. 141-142).

É chegado o momento de "Michel Viegnes: fantástico e poesia". O livro abordado intitula-se: L'envoûtante étrangeté. Le fantastique dans la poésie française (2006). Convém ressaltar que este é o tópico mais longo do livro de Camarani, vinte e três páginas, e também aquele que oferece maior dificuldade de leitura. Para o autor, "o fantástico não é um gênero, mas uma categoria estética, como o grotesco, o trágico ou o cômico" (p. 146). Tomando Irène Bessière como referência, Viegnes afirma que, segundo palavras da professora araraquarense, "é próprio do fantástico atribuir a mesma inconsistência ao real e ao sobrenatural: em vez do jogo de dualidades - natural/sobrenatural, razão/ilusão, lucidez/loucura - há a neutralização de todas essas noções" (p. 146). Apresenta "La nuit de décembre", poema de Musset, como exemplo da temática do duplo a se repetir no decorrer do poema de maneira 
lírica e angustiada. "La fontaine du cimetière", poema de Gautier, é analisado verso a verso, estrofe a estrofe de maneira a mostrar que existe "uma articulação complexa entre descrição, poesia e fantástico" (p. 148) capaz de "reinterpretar o universo referencial, de reconfigurá-lo segundo as grades hermenêuticas da linguagem" (p. 148). Os motivos constantes na poesia fantástica apontados pelo autor e cuidadosamente enfocados por Camarani, atendo-se a poemas nos quais cada um deles é analisado por Viègnes, são os seguintes: (a) quimera; b) sombras, espectros, fantasmas, almas de outro mundo; c) lugares; d) trevas; e) vozes.

"David Roas: em busca dos limites do real" é o derradeiro tópico do terceiro capítulo. O autor faz-se presente através de duas obras: Teorias de lo fantástico (2001) e Tras los limites de lo real (2011). Para o autor, segundo Camarani, o fantástico é "uma categoria estética multidisciplinar, abrangendo literatura, cinema, teatro, vídeo games" (p. 165). Para defini-lo, trabalha, em sua obra de 2011, com quatro conceitos: a realidade, o impossível, o medo e a linguagem. Ana Luiz Silva Camarani desenvolverá esses conceitos de maneira progressiva, unindo, de forma muito clara, o que é afirmado nas duas obras de Roas. Outros estudiosos fazem-se presentes nesse tópico: Martha J. Nandorfy, Rosalba Campra, Roger Bozzetto, Teodosio Fernández, Rosie Jackson, Susana Reiz, Schneider, Juan Herrera Cecilia, Rodríguez Hernández.

O quarto capítulo de A literatura fantástica: caminhos teóricos é dedicado a dois estudiosos brasileiros: José Paulo Paes (1926-1998) e Selma Calasans Rodrigues. "Introdução" à antologia de contos fantásticos organizada por Paes, Os buracos 
da máscara (1985), e o ensaio introdutório à obra Gregos \& Baianos (1985), intitulado "As dimensões do fantástico", constituem o corpus do estudioso paulista analisado por Camarani. Ressalta seu conhecimento da teoria todoroviana e sua opção pela definição de fantástico presente na obra de Irène Bessière. Ressalta a seleção por ele efetivada de contos fantásticos: Hoffmann, Poe, Gautier, Bécquer, Villiers de L'Isle Adam, Dickens, Maupassant, H. H. Munro, Jean Lorrain, Kafka, Murilo Rubião e José J. Veiga.

Selma Calasans Rodrigues, por sua vez, faz-se presente por sua obra de 1988: O fantástico. Trata-se, como ressalta Camarani, de obra "da coleção Princípios, o que pressupõe que seja para iniciantes" (p. 187). Como tal, a estudiosa, segundo a professora da UNESP, dá bem conta de sua tarefa, optando pelas colocações de Irène Bessière sobre $o$ assunto e revelando conhecimento da obra de Todorov. O maravilhoso surrealista, através da referência a André Breton, o realismo mágico, por ela denominado realismo maravilhoso, segundo o título da obra de Irlemar Chiampi, através de Alejo Carpentier, Gabriel García Marques, Juan Rulfo, fazemse presentes. Jorge Luis Borges e Julio Cortázar também são apresentados como representantes da literatura fantástica que tem como cenário o espaço urbano.

Em suas considerações finais, Camarani retoma problemas e estudiosos que não foram devidamente abordados. É o caso do neofantástico e de Jaime Alazraki; do realismo maravilhoso e de Irlemar Chiampi; do realismo mágico não restrito à literatura hispano-americana e de William Spindler. 
Trata-se, como deve ter notado o leitor desta resenha, de trabalho árduo não apenas resultante de um ano dedicado ao pós-doutorado, mas de toda uma vida de pesquisa que se iniciou com dissertação de mestrado, seguida de uma tese de doutorado, ambas focada em Charles Nodier, contista e teórico do fantástico. 